\title{
PESQUISA AGROPECUÁRIA E AGRICULTURA FAMILIAR NO BRASIL
}

Rohério Fencira dos Santos'

Pedro Carlos Gama da Silva ${ }^{2}$

INTRODUÇÃO

A agricultura brasileira passon a conviver, a partir de meados da lecada de 60 , com o paradigma que sc convencionou chamar mundialmente de "modernizaçáo da agricultura', que correspondia efetivanente à integração da agricultura ao processo de acumulação de capital $^{3}$. Isto ocorreu com a cfetiva participação do Estado, que através de suas políticas de crédito, subsídios, pesquisa, tecnologia c assistência técnica, viabilizon as maiores propriedades agropecuárias, principalmente àquelas localizadas em terras melhores; a indústria para a agricultura, que para esta produzia máquinas, cquipamentos e insumos; e a agroindustria, que processava as Matérias-primas agrícolas. Com a expansão do processo de moderuização, uma parte menor da pequena produção agrícola faniliar conseguiu participar deste processo, subordinando-se à agroindústria, como ocorreu com a

1 Dontor en economia, pesquisidor da LMBRAPACNPA a professor do Curso cle Mestrado em Fconomia Rural da UPPB, Caxil [ostal 17/1, 58107-720, Campina Cirande, l'B. I:-nail: roberio(a)copatembrapabr.

2 Mestro en conomia, pesfuisador da EMBRAPNCPATSA, Caixa Postal 23, Petrolina, PE. F-mail: pgatma(o) cpatsa.cmbrapabr.

${ }^{3}$ Ver Santos, $1986: 20-34$. 
avicultura, sinocultura e alguns ramos da hortifruticultura, principalmente na regiáco (Centro-Sul do país, e às cooperativas, caso da soja e trigo, por exemplo. Enquanto isso, os produtores menos capitalizados, relegados a terras menos férteis, utilizando práticas tradicionais c explorando mão-de-obra familiar para subsistir e produzir um pequeno excedente comercializado para os mercados urbanos, garantiam preços baixos para os produtos alimentares da cesta básica dos trabalhadores brasileiros.

Na década de oitenta, chamada de perdida para a economia brasileira, que entrou em crise profunda após os dois choques do petróleo co da taxa de juros, 'o sucesso da sua agricultura, quando medido pela obtenção de supersafras, mesmo con a retirada de subsídios do crédito rural, levon alguns autores 'menos cuidadosos' a afirmarem que a agricultura brasilcira teria encontrado uma estrutura produtiva tecologicamente consolidada e capaz de reagir a estímulos de mercado. No entanto, uma análise mais atenta, pode levar a conclusão que o crédito rural subsidiado foi, na verdade, substituído pelo crédito dirigido, via preços mínimos, que implica em maior seletividade dos beneficiários, que passaram a ser mais subsidiados que antes (Martine, 1990:8). Assim sendo, na década de 80, com a escassce, a disputa pelos recursos públicos limitou-se aos grupos mais modernos, aqueles integrados aos complexos agroindustriais.

As constataçós acima deixam claro a manipulação do Estado pelos setores oligepólicos (indústria para a agricultura e agroindústria), que sío, na verdade, os setores mais importantes na acumulação de capital na agricultura. (O) acesso aos recursos do Estado, dessa forma, năo é determinado pela capacidade e performance produtiva, mas sim, regulado pelo poder de pressão dos diferentes segmentos de um pequeno subgrupo dominante. Os que alardam a eficiência dos grandes estabelecimentos agropecuários brasileiros, deveriam deixar claro que grande parte desta eficiência é política c não conômica ${ }^{4}$.

En meados da década de 90, o efeito atual do modelo de modernização da agricultura brasileira fica aparente. Aquela parte inte-

\footnotetext{
4 Ver maiores detal les desta discussão em Martine (1990:17-30).
} 
grada ao complexo agroindustrial está consolidada, apesar de se cncontrar em estado de crise cíclica, devido, principalmente, ao predomínio de políticas neo-liberais encontradas nos três últimos goyernos.

Como não poderia ser difcrente, foi diminuída a participação do Estado na agricultura com a redução significante do subsidios. $\Lambda$ outra parte, a maior, hoje classificada de agricultura familiar, aqui entendida como aquela que concentra sua produção én produtos com baixo nível de processamento industrial, que constiucm o grosso da cesta básica da maior porção da população brasileira, encontra sérias dificuldades para continuar existindo dentro do paradigna da modernização da agricultura.

O objetivo deste trabalho é tecer alguns comentários sobre a agricultura familiar enquanto dependente da pesquisa agropecuária pública, dentro do novo modelo de atuaçáo que vem sendo adotado na Empresa Brasileira de Pesquisa Agropecuária-EMBRAPA, empresa líder naquele segmento de pesquisa.

\section{PESQUISA E AGRICULTURA FAMILIAR}

A mudança técoica na área agronônica envolve investimento com elevado periodo de maturaçáo, necessidade de pessoal qualificado c grande grau de incerteza quanto aos resultados. No que se refere a tecnologia genética ela ainda é baseada, em grande parte, nas técnicas clássicas de melloramento, que preservan a reprodutividade das sementes melhoradas, tornando praticamente impossivel a aplicaça de um sistema de patentes, ou seja, de se exduir os não-pagantes, mas usufruidores do conhecimento. Assim sendo, o elcvado custo resultante do esforço de pesquisa não é recompensado por um lucro duradouro, já que este ć rapidamente erodido por aqueles não-pagantes dos esforços de pesquisa (Lemos, 1995:7.5).

Existe pois, uma barrcira biológica para a apropriação privada dos frutos do progresso técnico no melhoramento genético. Mesmo se fosse conferido o direito de patentes, restaria ainda o problema da limitaça de acesso ao uso de novo conhecimento, já que o custo marginal social do uso de un conhecimento é zcro (Melo, 1978:54). 
- $A$ divisão do trabalho entre pesquisa pública e privada tem evohudodeacordo com a capacidade do capital estabelecer algum tipo de bartétra à entrada na tecnologia de melhoramento genético. Onde istonange épossivel, tem-se enfatizado o papel da pesquisa agronômicar como isendo uma função primordial do setor público (Lemos, $-1995.575)$ \& $O$ Estado brasileiro assumiu efetivamente esta função em 19972, , com a criação de un forte sistema nacional de pesquisa agropecuária liderada pela EMBRAPA. Ele optou assim pela criação de instituiçóes públicas de pesquisa, que assumiram efetivamente o trabatho de geração c/ou adaptação e difusão de tecnologias agropecuárias no Brasil. Com a opça por este modclo, ontado brasileiro ocupou o espaço deixado de lado pela iniciativa privada, por não implicar en retorno econônico para os investimentos realizados.

É verdade que, entre as contribuçoes do sistema EMBRAPA para a pesquisa agropecuária, estāo inclúdas aquelas atividades que viabilizaram o pacote da revolução verde para o Brasil, mas que foi uma contribuição que náto teria se efetivado pela iniciativa privada, já que os custos eram individualizados e os retornos socializados. Mas, a EMBRAPA também contribuiu, com repcrcussão internacional, com a geração de tecnologias que implicaram na redução de custos agrícolas, com diminuição do uso no campo de insumos industriais, como, por exemplo, o aumento da fixação de nitrogênio no solo através de bactérias nitrificantes e a utilização massal de inimigos naturais para combate a pragas.

Uma grande verdade fica aparente: A maior parte das tecnologias, geradas e/ou adaptadas pelo sistema EMBRAPA, não teriam sido efetivadas scm o aporte de recursos públicos para a pesquisa agropecuária (diversos trabalhos já foram escritos mostrando o alto retorno social destes investimentos) $)^{5}$.

No entanto, principalmente nos anos 90 , com a sucessão de governos de indoles neo-liberais, o sistema EMBRAPA passou a acumular perdas de aporte de recursos financeiros. Alguns dados de 1995

5 Ver, entre outros, CRUZ a al. (1982), ROESSING (1984), AMBROSI e (RULZ (1981), BARBOSA et al. (1988) e SANTTOS et al. (1989). 
deixam claro este fato ${ }^{6}$. Do total aprovado para os 15 progranas de pesquisa da EMBRAPA, somente $42 \%$ foram repassados; dos recursos totais que seriam liberados para a EMBRAPA, foram contingenciados, em dezembro de 1995, recursos que superam o valor orçado para outros custeios totais para todo ano de 1995.

Esta expressiva redução de aporte de recursos para o sistema EMBRAPA, corresponde a uma fuga da responsabilidade do Estado brasileiro perante a geração e/ou adaptação e difusáo de tecnologia para a agropecuária do país, responsabilidade efetivamente assumida em 1973, e que, pelo exposto até o momento, inplicará em näo atendimento na execução de una série de pesquisas essenciais para a agropecuária nacional.

Para fazer face a redução do aporte de recursos financeiros públicos, as diretorias da EMBRAPA, a partir de 1990, passaram a adotar uma política mais agressiva na busca de recursos financeiros de fontes alternativas. Isto pode ser observado claramente nos projetos estratégicos que tratam do sistema de qualificação por resultados e desenvolvimento de vendas de processos, serviços e produtos. No primeiro,

"o objetivo é desenvolver e implantar um sistema de gratificą̧âo que premie umidades..., equipes de trabalho e empregados (individualmente), quando stperarem metas operacionais... e ampliarem a captaçẵo de recursos" (EMBRAPA, 1995a).

No segundo, um dos objetivos é

"conscientizar a comunidade embrapiana, quanto à importância de ampliàr a arrecadação de recursos próprios" (EMBRAPA, 1995b).

Menciona-se neste projeto que

. "apenas 10\% do orçamento anual da EMBRAPA são recursos próprios.. O que preoclipa, neste particular, é que a arrecadação própria 
da EMBRAPA não cresce... E durante esse período (mais de 20 anos), a Empresa cresceu em número de midades, melhoron a infra-estrutura dessas unidades, incrementon a quantidade e qualidade de snas máquinas e equipamentos, crescen na quantidade e na qualificação dos seus funcionários..." (EMBRAPA, 1995b).

É claro que medidas de incentivo para aumentar a arrecadação da EMBRAPA devem ser elogiadas. Mas, näo se pode esquecer que a iniciativa privada não investe onde não existe alternativa de retorno econômico. E na agropecuária este campo é vasto. Por este motivo, como ja afirmado neste trabalho, a EMBRAPA foi criada.

Recentemente, passou-se a exigir das unidades descentralizadas da EMBRAPA, o atingimento de arrecadação de recursos próprios a partir de um mínimo previanente estipulado. () não atingimento da meta pré-fixada implicará en 'puniçōes' para a unidade, que atingirá inclusive os empregados nela lotados.

Mas, o problema maior encontrado no não atingimento destas metas é exatamente o porquê do seu não atingimento. Existirão dificuldades para as unidades descentralizadas que trabalham com produtos com menores índices de processamento agroindustrial e para aquelas que trabalham com regiōes com maiores riscos climáticos, já que os recursos privados são muito mais dificeis de screm conseguidos. Estas unidades poderão ser entăo prejudicadas exatamente por estarem exercendo suas atividades de pesquisa em produtos e/ou regiôes onde se torna ainda mais importante a atuação da pesquisa píblica.

A competição por recursos financeiros, por parte das unidades descentralizadas da EMBRAPA poderá provocar outro tipo de problema de igual ou maior importancia que os acima citados. O abandono do segmento da agricultura familiar, ou mais especificanente, das suas categorias chamadas de transição e periférica, que abrangem, no Brasil, 71\% dos estabelecimentos agropecuários existentes (FAO) 1994), exatamente quando o Ministério da Agricultura, do Abastecimento e da Reforma Agrária cria, "em favor do respeito e do apoio à agricultura familiar", o PRONAF - Programa Nacional de Fortalecimento da Agricultura Familiar. E a LMBRAPA tem entre seus proje- 
tos cstratégicos, um que trata especificamente da agricultura familiar, que clege o programa de Sistemas de Produção da Agricultura Familiar como sistema de articulação para valoriação das açóes de apoio ao PRONAF (EMBRAPA, 1995b).

Este programa não toi criado por acaso. Algumas constataçóes são bastante indicativas do potencial de viabilização da unidade agrícola familiar, entre $\mathrm{elas}^{7}$ :

- Seu papel 'amortecedor' da violência das crises cconônicas, face a sua capacidade de absorção de mão-de-obra (Adant \& Altafin, 1991). $\Lambda$ perspectiva desse cnfoque considera o fato comprovado de que é mais conômico para a sociedade manter a atividade de una população agrícola numerosa, do que sustentar novos desempregados urbanos. Estimativas da FAO) (1994), mostram que os sistemas de produção mais intensivos e diversificados da agricultura familiar, permitem a manutenção de quase sete vezes mais postos de trabalho por unidade de área que na agricultura patronal. A agricultura familiar requereria apenas 9 ha para gerar um emprego, contra 50 ha requeridos pela agricultura patronal. () estrato de estabelecimentos de até $10 \mathrm{ha}$, onde a agricultura familiar predomina (principalmente na rcgiáo Nordeste), mesmo correspondendo a apenas $2,6 \%$ da área total, ocupa 10 vezes mais pessoas que o estrato de mais de $1.000 h a, 43 \%$ da área total. Os estabelecimentos de menos do 50 ha, $90 \%$ dos quais empregam mão-de-obra familiar, ocupam 16 milhóes de pessoas, o que significa $70 \%$ de todos os ativos do setor (IBGE, 1985);

- Pela valorização prioritária das potencialidades locais, a agricultura familiar constitui-se numa garantia de estabilidade de produça coferta de certos produtos básicos da alimentação, de menor interesse ou não contemplados pela agricultura patronal. Os estabelecimentos com área inferior a 
10ha, boa parte deles de unidades familiares, ocupando pouco mais de $2 \%$ da área total, são responsáveis por cerca de $15 \%$ da produção nacional de milho, $28 \%$ da de feijão e $36 \%$ da de mandioca. Acrescente-se a isso, o seu papel de, em reduzindo o êxodo rural, limitar as transformaçôes dos hábitos alimentares induzidas pelo modo de vida urbano, muitos deles mantidos as custas de divisas (Delpeuch, 1989);

- Sua possibilidade de poder gerar, em muitos cultivos, produtos de melhor qualidade e a um menor custo. É reconhecida a capacidade do modelo familiar de gerar um produto de qualidade superior, quando comparado a outro similar, produzido em grandes áreas, geralmente mecanizadas. Na realidade, é o mesmo que comparar um produto artesanal com outro produzido em série. Esta vantagem é válida para um sem número de produtos agrícolas que demandam um trabalho mais delicado, mais arriscado, exigente em precisão, en capacidade de rápida reação ao imprevisto e em permanente disponibilidade;

- Seu favorecimento, quando há segurança de posse da terra, a uma melhor preservação do meio ambiente e a uma gestão mais ordenada do espaço, cm função das características do seu modelo diversificado de produção, em contraste com o modelo produtivista de monocultivo predominante na agricultura patronal ou capitalista.

A prioridade da pesquisa agrícola é uma das condiçôes fundamentais a un programa de viabilização da agricultura familiar no Brasil. Apesar de todas as limitações que afetam este importante segmento da agricultura brasileira, a inovação tecnológica, juntamente com os procedimentos que visam a sua adaptação, ao lado de um esforço de capacitação e de organização dos agricultores, constitui, segundo a FAO (1992), o tripé bâsico da estratégia para um desenvolvimento mais endógeno e protagônico do referido segmento, permitindo que assuma, no futuro, o papel correspondente a sua importância e ao seu potencial. Mais ainda, o desenvolvimento tecnológico, numa primeira etapa, deverá ser efetuado em consonância também com a 
racionalidade própria da economia da produção familiar e não apenas con aquela requerida pelo capital, pelo menos para aqueles estratos mais fragilizados, não contemplados com as políticas públicas.

Dentro desse enfoque, as inovaçōes tecnológicas deveriam favorecer a poupança de capital, maximizando, até onde possível, o aproveitamento da força de trabalho disponível. A capacitação deveria privilegiar a ampliação dos conhecimentos e habilidades produtivas, elevar a produtividade da māo-de-obra rural e, sobretudo, estimular as mudanças de atitudes e valores (autoconfiança, nível de aspiração, responsabilidades, etc.). A organização dos agricultores e da produção teria como finalidades precípuas, a redução da dependência externa da unidade familiar, a redução dos custos de produção e atmento do valor de venda de seus produtos, a ampliação do acesso aos serviços de apoio, a criação de serviços próprios e até a viabilização da economia de escala.

\section{CONSIDERACÕES FINAIS}

Parece bastante claro que o paradigma da revolução verde já não é suficiente para provocar impactos significantes na agropecuária mundial. $O$ uso de insumos industriais no campo já não consegue provocar aumentos significantes nas produtividades da terra e trabalho, ficando cada vez mais claro seu dano ao solo e meio ambiente. Pode-se argumentar que, no caso do Brasil, principalmente junto à agricultura familiar, ainda é possível gerar impactos significantes com a revolução verde, já que a imensa maioria deste segmento ficou fora do processo. No entanto, nos dois últimos parágrafos acima procura-se deixar claro que, na busca de alternativas para a imensa maioria da agricultura familiar, as disponibilidades ainda são anteriores ao paradigma da modernização da agricultura. Isso é bastante lógico, jả que o capital industrial ainda não encontrou um locus de acumulação junto a maior parte desse segmento, nem o Estado optou em tornar isto, via políticas públicas, viável.

O que existe é uma incompatibilidade entre a política do Governo Federal que dá ênfase a necessidade de se apoiar a agricultura familiar e a política deste mesmo Governo, que reduz significativa- 
mente os recursos alocados à pesquisa agropecuária pública, forçando os dirigentes da EMBRAPA à necessidade de recorrer aos rccursos financeiros privados, que direcionarão aquela mesma pesquisa agropecuária pública cada vez para mais longe da considerada prioritária (pelo Governo) agricultura familiar. Corre-se pois, o risco dos benefícios da pesquisa agropecuária pública seren direcionadas, cada vez. mais, para um grupo restrito de usuários, em detrimento da inensa maioria dos produtores rurais $c$, o que é mais importante, dos consumidores, já que os esforços de geração e transferência de tecnologia tenderão a atender, prioritariamente, a demanda daqueles que podem pagar, os grandes produtores rurais e agroindustriais.

\section{BiBLIOGRAFIA}

ADANT, P.; $\Lambda$ LTAFIN, I., Agricultores paysames an Bresil: enguele sur in enjen mational (S.I.), Foundation pour le progress de lHomme, 1991. IV;

AMBROSI, I.; CRUZ, E. R., Taxa de rotomo dos recursos aplicados em pesquisa no Cenlro Nacional de Pesquisa de Trigo, Passo Fundo - RS, EMBRAPA - CNPT, 1984, 27p;

BARBOSA, M. M. T. L.; CRUZ, E. R. da; ÁVILA, A. F. Q., Beneficios sociais e econômicos da pesquisa da EMBRAPA: umu realualiăo, in: YECANIANTZ, L. (org.), Pesquisa Agropecuatia, questionamentos, comsolidağon e perspectivas. Brasília - DF, EMBRAPA - DPU, 1988, pp. 339-52;

CRUZ, E. R. da; PALMA, V; ÁVILA, A. F. D., Taxas de relorno dos investimenttos da EMBRAPA, investimentos tolats e capilal fisico. Brasilia - Dr, EMBRAPA - DII), 1982. 47p. (EMBRAPA-DOM. Documentos, 1);

DELPEUCH, B., Pon des Agricullures Paysannes, (S.1.), Foundation Pour le Progress de L'Homme, 1989. 31 p.;

EMBRAPA, Centro de Pesquisa Agropecuária do Trópico Semi-Árido (Petrolina, PE), Programa: Sistemas de Produçoo da Agricultura Familiar, Petrolina, s.d.. 18p.;

- (Brasília, DF), Estratégia Gerencial da EMBRAPA, gestão 95/98, Brasilia, 1995a. 11.p.;

(Brasília, DF), Projetos e Processos Prionitánios da EMBRAPA, Brasilia, 1995b. 27p;

FAO, Escritório Regional para América Latina e Caribe, Desenvolvimento Agropecuánio; da dependência no protagonismo do agricultor, Santiago, $2^{\text {a }}$ ed., 1992, 24p.; 
- Oficina Regional para América Latina y el Caribe, Generacion de Tecnologias Adecuadas al desarollo Rural. Santiago, 2.ed., 1988, 41p., (FAO, Série: Desarrollo Rural, 4);

IBGE, Censos Agropemánios, Rio de Janeiro - RJ, 1985;

LEMOS, M. G., Organizaço Agroindustrial, entrada em tecnologia e liderança de merados; o caso brasileimo, in: RAMOS, P.; REYDON, B. P. (ogs), Agropeaúria e agroindustria no Brasil; ajuste, situaço atual e perspectivas, Campilas - SP, ABRA, 1995, 2.54p;

MARTING, G., Fases e faces da modernização agrícola brasileira, Brasilia-DF, Planejamento e Polítios Públicas, 01(1): 3-44, 1989;

MELO, F. B. H. de, Agnichlina; incenteza e disponibilidade de tecnologia, Săo Panlo - SP, USP/IPE, 1978 (Tese Livre Docência);

ROESSING, A. C.. Taxa intema de retomo dos investimentos em pesquisa de soja, Londrina - PR, 1984, 37p. (EMBRAPA - CNPSO, Documento, 6);

SANTOS, R. F. dos, Presenga de Viéses de Mudança Técnica na Agricultura Brasileina, São Paulo - SP, USP/IPE, 1986, 176p., (USP/IPE, Ensinos Econômi$\cos , 63)$;

SANTOS, R. F. dos; CALEGAR, G, M.; SILVA, V. V. da; BARROS, M. A. L.; I.IMA, J. O. A. de A.; MOTTA, J. da S.; NETO, J. de S., Avaliaçăo Socioeconômica das Pesquisas da EMBRAPA na Regiño Nordeste, Brasilia - DF, EMBRAPA, 1989, 45p., (EMBRAPA - SEP. Documentos, 37). 